\section{Comment On: Visceral Obesity May Affect Oncologic Outcome in Patients with Colorectal Cancer}

\section{TO THE EDITORS:}

The authors of an article published in the Annals of Surgical Oncology found that there was no influence of body mass index (BMI) and visceral adiposity on overall survival after treatment for colorectal cancer, but a trend to significance of being overweight (BMI $>25 \mathrm{~kg} / \mathrm{m}^{2}$ ) with reduced disease-free survival (DFS, $p=0.064$ ). ${ }^{1}$

Patients were then classified according to a visceral fat area (VFA)/subcutaneous fat area (SFA) ratio. With no standard values for this ratio, patients were then divided according to percentiles of VFA/SFA ratio. Using this division, the authors were then able to find a significant reduction in disease-free survival (DFS) in patients with high VFA/SFA ratio (above 50 percentiles, $p=0.008$ ).
It is interesting that this significant result was obtained only after reclassification of patients into quartiles. Body mass index is not always an accurate measure of actual obesity, and one wonders if it is possible that, in using BMI in the study, obese/nonobese patients were initially classified incorrectly; on analysis of the paper, it is clear that the high-VFA/SFA group comprised 81 patients, whilst the initial overweight (BMI $>25 \mathrm{~kg} / \mathrm{m}^{2}$ ) group had only 46 , suggesting flow of patients initially deemed as of "normal weight" into this group after this criterion was applied.

\section{Gurpreet Singh-Ranger, BSc, MSc, MS, FRCS (Eng)} Colorectal Surgery, Whipps Cross Hospital, London, UK e-mail: gsinghranger@yahoo.co.uk

Published Online: 28 October 2009

(C) Society of Surgical Oncology 2009

\section{REFERENCE}

1. Moon HG, Joo YT, Jeong CY, et al. Visceral obesity may affect the oncologic outcomes in patients with colorectal cancer. Ann Surg Oncol. 2008;15:1918-22. 